\title{
Metodología para la elaboración de un plan de restauración postincendio en Chile: la experiencia del Parque Nacional de Torres del Paine
}

\author{
Methodology for a post-fire restoration plan in Chile:
} The experience of the Torres del Paine National Park

Rafael $\mathrm{M}^{\mathrm{a}}$ Navarro Cerrillo ${ }^{1}$, Fernando Olave

Ortiz $^{2}$, Antonio Hayas ${ }^{1}$, Miguel Castillo ${ }^{3}$

\section{Resumen}

El uso de imágenes procedentes de sensores remotos para la evaluación y restauración de áreas afectadas por grandes incendios es uno de los aspectos que ha experimentado un mayor desarrollo en los últimos años. En este trabajo se presenta la metodología elaborada por la CONAF y la Universidad de Córdoba (España) para generar la cartografía básica orientada a los planes de restauración en áreas incendiada en Chile. Dicha metodología se aplicó al incendio del Parque Nacional de Torres del Paine (2005) a partir de imágenes de los sensores Landsat ETM+ y ASTER, también del uso de clasificaciones supervisadas y del índice delta NBR (Normalized Burnt Ratio). El proceso de datos permitió elaborar una representación cartográfica de la vegetación previa al incendio (Coeficiente Kappa 0,75), la superficie recorrida por el fuego (17.138 ha) y la severidad de los daños producidos por el incendio (Coeficiente Kappa 0,73). Los resultados permitieron elaborar una propuesta de restauración de la zona afectada por el fuego para el PN Torres del Paine. La metodología empleada ha mostrado la utilidad y versatilidad de las imágenes de resolución espacial media y del índice normalizado de diferencias NBR para la obtención de una cartografía básica de áreas incendiadas en Chile, como instrumento de apoyo para proponer acciones de restauración y orientación de medidas técnicas necesarias para la ejecución de labores de repoblación forestal en campo.

Palabras clave:

incendios forestales, vegetación patagónica, severidad, Normalized Burn Ratio.

\section{Abstract}

The use of remote sensing data for assessment and restoration of areas affected by wildfires is one aspect that has undergone further development in recent years. In this paper the methodology developed by the CONAF and the University of Córdoba (Spain) to generate the basic cartography oriented restoration plans in areas burned in Chile is presented. This methodology was applied to the fire of the National Park Torres del Paine (2005) using Landsat ETM + and ASTER images and supervised classifications based on delta NBR (Normalized Burnt Ratio) index. A map of prefire vegetation (Kappa coefficient 0.75 ), the area covered by the fire $(17,138 \mathrm{ha})$ and the severity of the damage caused by the fire (Kappa coefficient 0.73) were obtained. Results were applied to a proposal to restore the area affected by the fire. The methodology has demonstrated the versatility of the medium spatial resolution images and NBR index for mapping burned areas in Chile. This information was used to support the restoration of

1 Depto. Ingeniería Forestal, DendrodatLab Universidad de Córdoba. Campus de Rabanales, Crta. IV, km. 396, 14071 Córdoba. Spain. E-mail: rmnavarro@uco.es $\gg$

2 Corporación Nacional Forestal, Chile. Paseo Bulnes 285, Santiago Chile

3 Laboratorio de Incendios Forestales. Universidad de Chile. Casilla 9206, Santiago de Chile. 
ecosystems damage by the fire of Torres del Paine National Park.

\section{Key words:}

wildfire, Patagonian vegetation, severity, Normalized Burn Ratio.

\section{INTRODUCCIÓN}

En Chile, el fuego, de manera natural o artificial, ha contribuido a la modificación permanente de formaciones vegetales y ecosistemas asociados, especialmente en los últimos 150 años (Castillo, 2006). Aun cuando el país ha presentado importantes avances en materia de prevención $e$ investigación en manejo del fuego, persiste la amenaza permanente de la ocurrencia de nuevos y graves incendios en vegetación nativa, muchos de ellos de alta complejidad en su propagación y control. La superficie media anual afectada por incendios forestales en Chile en los últimos quince años (2000 - 2015) ha sido de 56.473 ha, pero con valores extremos que han variado entre 10.921 y 105.992 ha año ${ }^{-1}$ (CONAF, 2015). Un porcentaje reducido de estos incendios (entre $0,09 \%$ y $1,61 \%$ del total para el período antes señalado) ha excedido las 1.000 ha, destacando los incendios sucedidos en 2005 y 2012 en el Parque Nacional Torres del Paine (15.474 ha $y$ 17.138 ha sucesivamente), encontrándose incluso episodios de fuegos muchos más extensos como el sucedido en 1999 en Sierras de Bellavista (Región de O'Higgins) en donde se quemaron casi 25.389 ha de bosque nativo, principalmente formaciones de roble y ciprés de la cordillera (Castillo, 2006). El Gobierno de Chile ha impulsado el desarrollo del programa de protección estatal en manejo del fuego, sin embargo, los recursos asignados siguen siendo insuficientes para enfrentar de manera adecuada la gestión del manejo del fuego. Muchos son los factores que pueden explicar la realidad de los incendios forestales en Chile, la fragmentación de paisajes, el impacto del turismo, el aumento de la conectividad, de la intencionalidad en la ocurrencia de incendios y el aumento de la condición de peligro por la prolongada sequía que ha afectado a Chile Centro-Sur en los últimos años, han acentuado aún más el problema (Castillo et al. 2014).

Sumado a lo anterior, existen carencias en investigación aplicadas a distintas áreas del conocimiento en manejo y ecología del fuego. Uno de los temas necesarios a fortalecer, es justamente la restauración de áreas afectadas por el fuego, con énfasis en ecosistemas nativos. Los medios destinados a la restauración de áreas forestales quemadas han sido, hasta hoy, muy escasos, y salvo en casos excepcionales, la restauración se ha dejado en manos de la regeneración natural, insuficiente en buena parte de los casos (Fernández et al. 2010).

Según las características físicas y bióticas del medio, la intensidad con la que se ha desarrollado el incendio y las condiciones posteriores en las que se ha desenvuelto la regeneración natural, la evolución del área incendiada puede dar lugar al desarrollo de ecosistemas muy diversos. En este contexto, la severidad post fuego puede ser calificada de acuerdo a distintas escalas de afectaciones, tal como lo han propuesto Brown et al. (2004) quienes asocian los períodos de fuego (recurrencia) a escalas de severidad; también Keeley (2009) quien al evaluar ecosistemas afectados por el fuego enuncia que los principales indicadores de la severidad se expresan en el suelo, especialmente en el daño producido en los primeros centímetros de estrato orgánico como también a la estructura aérea y radicular de las plantas sobrevivientes al paso del fuego. Los efectos del fuego sobre la vegetación (y otros factores del medio, como la fauna, las características físico-químicos del suelo, o su componente biológico), dependen de factores intrínsecos que vienen definidos por el régimen del incendio (frecuencia, intensidad, tamaño y forma del incendio, y época) y de otros propios de las condiciones físicas del medio y de la vegetación afectada (clima, geomorfología, topografía, suelos, composición florística y fenología) (Kozlowski, 2012). Una incidencia reiterada de incendios puede ocasionar graves problemas ambientales, sobre todo en aquellos ecosistemas representados por biotopos sensibles a la erosión y lixiviación de nutrientes, así como sobre aquellos biomas caracterizados por la presencia de la vegetación. La pérdida del potencial biótico es el impacto más importante de los incendios forestales, y la consecuente desaparición de la vegetación da lugar a alteraciones de la biodiversidad (Kozlowski, 2012), la transformación del comportamiento 
hidrológico de las cuencas (Onodera et al. 2011), e impactos sobre las comunidades biológicas de los ecosistemas y los paisajes (biomas) asociados (van Wagtendonk et al. 2004), y en muchas ocasiones es una fuente peligrosa de enfermedades y plagas. A corto plazo, buena parte de estos efectos son difíciles de corregir; sin embargo, sí es posible corregir parte de esos impactos mediante técnicas de restauración de la vegetación (Vallejo et al. 2012), y de restauración paisajística e hidrológica (Madsen et al. 2012).

El consenso que existe en cuanto a la urgente necesidad de recuperar las zonas afectadas por grandes incendios, no es tan unánime cuando se trata de decidir sobre las actuaciones restauradoras más adecuadas. Los sectores técnicos recomiendan una inmediata intervención sobre estas áreas, tanto en lo que se refiere a las labores de conservación del suelo y lucha contra fenómenos erosivos acelerados; así como sobre la vegetación, mediante actuaciones silvícolas y de repoblación forestal (Castro et al. 2009). Por otro lado, otros sectores cuestionan el efecto de estas actividades, tanto por el posible efecto negativo (induciendo o acelerando procesos erosivos), como por el propio impacto de las nuevas plantaciones (Vallejo et al. 2012).

La dificultad técnica, y el costo creciente de muchas de las acciones de repoblación forestal, obligan a considerar la restauración de áreas incendiadas en una perspectiva no sólo espacial, sino también temporal, donde las intervenciones externas deben estar adecuadamente planificadas en función de las condiciones ecológicas, y de la urgencia de las intervenciones (Gitas et al. 2012). Los métodos tradicionales de evaluación del impacto post-incendio sobre la vegetación basados en trabajos de campo, han mostrado ser muy costosos (en tiempo y recursos humanos), y de resultados limitados en grandes superficies y/o sistemas ecológicos muy complejos (HernándezClemente et al. 2007).

Los incendios forestales provocan una serie de cambios físicos (reducción o desaparición de la cobertura vegetal, cambios de color en la superficie, etc.) que se reflejan en la respuesta espectral de las cubiertas vegetales. Sobre esta base, se han desarrollado numerosos trabajos en los que la teledetección, y más concretamente sensores de diferente resolución espacial como
SPOT-Vegetation (Sankey et al. 2008; Gouveia et al. 2010), Landsat-TM y ETM+ (van Wagtendonk et al. 2004; van Leeuwen et al. 2008) o ASTER (Csiszar et al. 2004), se utilizan para cartografiar zonas quemadas (Brewer et al. 2005) y diferenciar grados de severidad dentro del área recorrida por el fuego (Escuin et al. 2003; 2006; Díaz-Delgado et al. 2003; Gitas et al. 2012).

El incendio que afectó al Parque Nacional de Torres del Paine el día 17 de febrero de 2005, en el sector del desagüe de la Laguna Azul, cubrió una superficie de 17.138 ha. Ante la gravedad de los daños producidos, la Corporación Nacional Forestal (CONAF) planteó la necesidad de elaborar una metodología para la evaluación de las áreas afectadas por grandes incendios que sirva de apoyo técnico para definir las actuaciones más adecuadas para su restauración. La CONAF, como administración responsable de la gestión y restauración de los ecosistemas forestales chilenos, viene proponiendo desde hace un tiempo medidas de actuación encaminadas a conservar y restaurar las zonas que se ven afectadas por incendios forestales. Dadas las necesidades actuales en lo que respecta a esta materia, este artículo presenta la metodología propuesta para la evaluación de las áreas afectadas por grandes incendios y la experiencia adquirida durante su aplicación a la restauración de las áreas afectadas por el incendio del P.N de Torres del Paine del año 2005. Se propone una metodología rápida, de fácil aplicación y de costo reducido para que la CONAF y los organismos competentes en materia ambiental puedan elaborar planes y proyectos de restauración de áreas afectadas por grandes incendios en Chile, cuya ejecución pueda mitigar los efectos directos e indirectos causados por los incendios forestales.

\section{METODOLOGÍA PARA LA ELABORACIÓN DE UNA CARTOGRAFÍA BÁSICA PARA LA RESTAURACIÓN DE LA VEGETACIÓN DESPUÉS DE UN INCENDIO}

En la literatura científica relacionada con la evaluación de grandes incendios se han propuesto diferentes estructuras metodológicas para la aplicación de la teledetección al seguimiento de los procesos de restauración post-incendio. Algunas tienen un fundamento principalmente silvícola- 


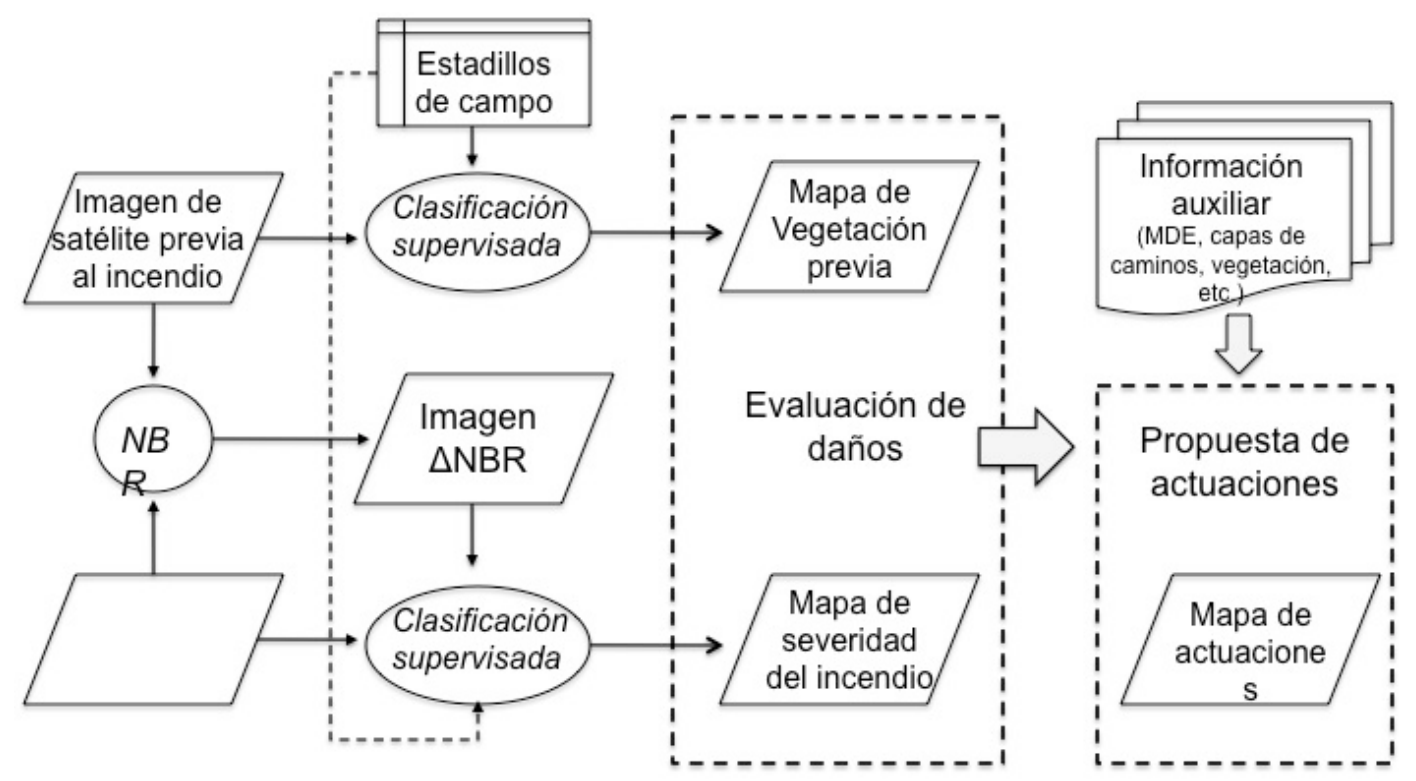

Fig. 1.- Proceso metodológico para la elaboración de una cartografía para la restauración de áreas afectadas por grandes incendios.

hidrológico (CMA 2006), paisajístico (Wittenberg et al. 2007), socioeconómico (Unit et al. 2011), o bien están relacionados con los impactos sobre los factores ambientales (Navarro Cerrillo et al. 2004; 2008; Alloza et al. 2014).

La metodología propuesta por la CONAF y la Universidad de Córdoba (España, Navarro Cerrillo et al. 2008) está orientada a elaborar las bases cartográficas necesarias para la restauración post-incendio de la cubierta vegetal (Fig. 1). La variedad de ecosistemas terrestres chilenos, así como la complejidad de situaciones que se pueden encontrar en áreas afectadas por incendios, hace difícil generalizar las actuaciones de restauración. Sin embargo, con una visión sintetizadora, sin que esto suponga la pretensión de simplificar, se pueden agrupar casos y situaciones en que las actuaciones de restauración puedan responder a pautas semejantes. Los principales pasos metodológicos propuestos son los siguientes (Fig. 1):

1. Definir con la mayor precisión posible la cartografía del área recorrida por el incendio a partir de la comparación de una imagen previa y posterior al incendio.

2. Generar una cartografía de vegetación previa al incendio a partir de bases cartográficas (fotografías aéreas y/o clasificación supervisada de imágenes de satélite) y de trabajo de campo.

3. Elaborar una cartografía de severidad de los daños producidos por el fuego sobre la vegetación mediante la clasificación supervisada de una imagen de satélite posterior al incendio.

4. Elaborar una cartografía de propuestas de restauración mediante la integración de las bases cartográficas obtenidas y de las fuentes básicas de información territorial disponible para hacer las recomendaciones de actuaciones orientadas a la restauración de las zonas afectadas.

\section{Generación de bases cartográficas}

Chile es un país que dispone de una importante base cartográfica territorial a través de distintos organismos: Instituto Geográfico Militar, CONAF-CONAMA (Catastro de bosque nativo 1997), mapa topográfico nacional escala 1:250.000 (Sistema Nacional de Información Ambiental de Chile), mapa de usos y coberturas vegetales escala 1:50.000 (Corporación Nacional Forestal de Chile), modelo digital de elevaciones de resolución espacial 90 × 90 m (Shuttle Radar Topography Mission), entre otras (Tabla 1).

En la evaluación de grandes incendios, 
se utiliza cada vez con más frecuencia imágenes procedentes de sensores espaciales (Gitas et al. 2012). En el caso concreto del incendio del P.N. de Torres del Paine (2005) se usaron tres escenas procedentes del sensor Landsat 7 ETM+ (Enhance Thematic Mapper Plus) en condiciones previas al incendio y dos escenas ASTER (Advanced Spaceborne Thermal Emission and Reflection Radiometer) consecutivas posteriores al incendio. Las imágenes fueron procesadas considerando la proyección geográfica del área de estudio (Datum WGS84), junto con un análisis y estandarización de las bandas espectrales para su uso en la interpretación de zonas quemadas (ver Navarro Cerrillo et al. 2008).

\section{Diseño del trabajo de campo}

Los trabajos de restauración post-incendio requieren del diseño de un inventario de campo adecuado a las necesidades de información que se va a utilizar, tanto para evaluar los impactos del fuego sobre la biodiversidad (en particular la vegetal) y la severidad de los daños, así como para verificar la cartografía de la vegetación antes del incendio y las principales características ambientales. Hay una amplia variedad de protocolos de muestreo desarrollados específicamente para los trabajos de restauración post-incendio (Daskalakou \& Thanos, 1997; Hernández-Clemente et al. 2009a), aunque éste ha sido uno de los aspectos más descuidado en las metodologías de evaluación de áreas incendiadas que priorizan el uso de la teledetección. Se han propuesto muchos tipos de inventario para la evaluación de daños posincendios, tanto aquellos estrictamente orientados a evaluar el impacto sobre la vegetación (Hudak et al. 2004), la severidad "física" del incendio (Alloza et al. 2014), o bien inventarios que sirven para levantar toda la información necesaria para evaluar de forma simultanea el impacto del incendio y la información necesaria para elaborar las actuaciones de restauración (Navarro Cerrillo et al. 2004; Hernández-Clemente et al. 2009b; Mitri \& Gitas, 2010).

En el incendio de Torres del Paine se levantaron dos tipos de parcelas: i) parcelas de entrenamiento destinadas a la clasificación supervisada para elaborar la cartografía de la vegetación previa al incendio y la cartografía de severidad de los daños $(n=80)$ y, ii) un conjunto de puntos de control $(n=132)$ para la validación de las cartografías obtenidas (Fig. 2). Las parcelas se correspondían con una superficie mínima cuadrada de 1 hectárea, homogénea en cuanto a composición y estructura vegetal, nivel de daños y topografía. Las variables medidas en cada parcela fueron las siguientes: (a) localización georreferenciada por medio de un GPS en coordenadas UTM para el Huso 18 Sur (Datum WGS84); (b) tipo de vegetación afectada: se asignó el tipo de vegetación según la

Tabla 1. Bases cartográficas disponibles para los estudios de evaluación y restauración post-incendio en el P.N. Torres del Paine.

\begin{tabular}{lcc}
\hline Cartografía & $\begin{array}{c}\text { Formato (escala/ } \\
\text { resolución) }\end{array}$ & Fuente \\
\hline Catastro forestal & CONAF-CONAMA \\
$\begin{array}{l}\text { Mapa topográfico de la Región de Magallanes y Antartica Chilena } \\
\text { Mapa de usos y coberturas vegetales del suelo de Magallanes y Antartica }\end{array}$ & Vectorial (1:250.000) & SINIA \\
$\begin{array}{l}\text { Chilena } \\
\text { Mapa de usos y coberturas vegetales del suelo del entorno Parque Nacional } \\
\text { Torres del Paine }\end{array}$ & Vectorial (1:50.000) & Universidad Austral de \\
Modelo digital de elevaciones & Chile \\
Modelo digital de elevaciones (sectores Lago Sarmiento y Laguna Amarga) & Shuttle Radar \\
Mapa de senderos del Parque Nacional Torres del Paine & (30 x 30 metros) & Topography Mission \\
Mapa de cuerpos de agua y ríos del Parque Nacional Torres del Paine & Vectorial (1:50.000) & Vectorial (1:50.000) \\
Mapa del área estimada del incendio & & SINIA \\
\hline
\end{tabular}




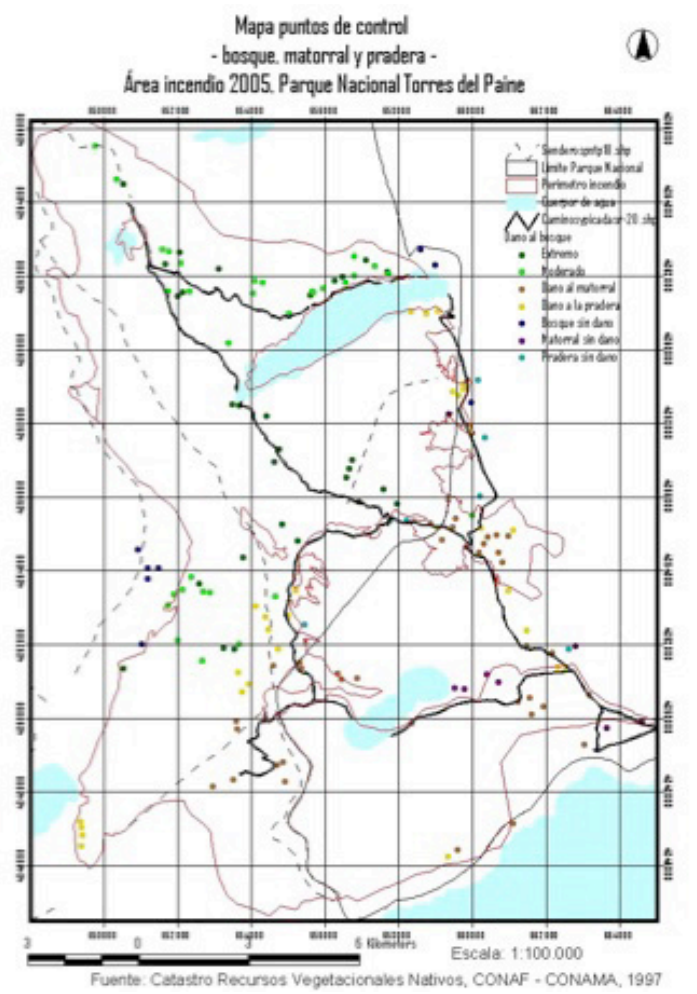

composición y la estructura de las comunidades presentes en la parcela, indicando en cada caso su composición específica; (c) severidad de los daño mediante estimación visual siguiendo el criterio propuesto por Navarro Cerrillo et al. (2004) ["nulo o leve"-no se aprecia ningún tipo de daños sobre la vegetación, "moderado"-incendio de superficie, con el arbolado y el sotobosque afectados, pero sin llegar a destruir la totalidad de la vegetación -fracciones de copas sin afectar-, quedando suficiente material vegetativo aéreo como para esperar una recuperación aceptable de la vegetación; y "extremo"-el fuego ha destruido el estrato arbóreo, arbustivo y matorral. Se realizaron fotografías panorámicas con una cámara digital, en las direcciones de los cuatro puntos cardinales en cada parcela. Además, se realizaron observaciones del lugar basadas principalmente en la observación de aspectos relacionados con el impacto del fuego sobre el suelo, así como la descripción de los daños sobre las comunidades afectadas.

Recomendaciones para la obtención de información básica

En Chile se dispone de importantes bases

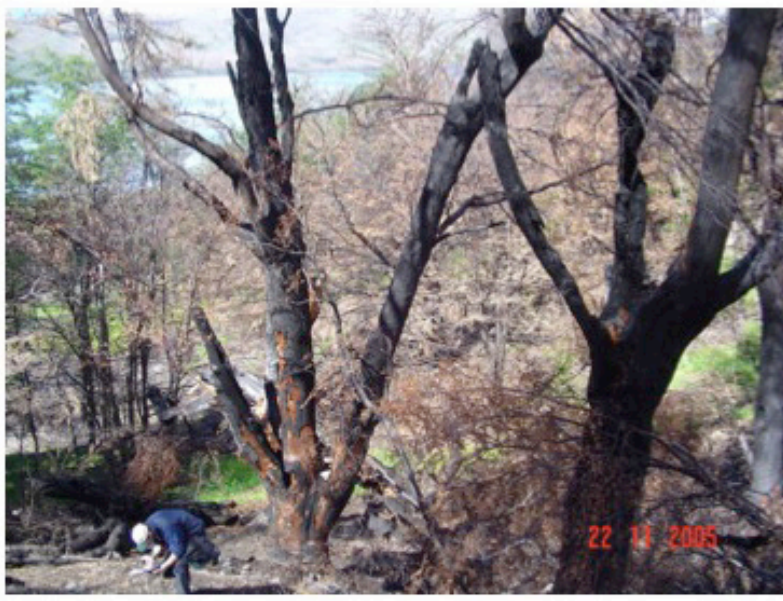

Fig. 2. Diseño del trabajo de campo realizado para la evaluación y restauración del incendio del P.N. de Torres del Paine. a) Distribución de los puntos de control empelados en la clasificación supervisada de tipos de vegetación y niveles de severidad del incendio, b) ejemplo de replanteo de una parcela de evaluación de la severidad y dinámica postincendio de la vegetación.

cartográficas de acceso público, que deben ser consultadas y/o adquiridas como paso previo a cualquier trabajo de evaluación y restauración de grandes incendios.

1. El acceso a imágenes procedente de sensores espaciales de media y alta resolución espacial se ha simplificado y reducido en costo, lo que ofrece una herramienta imprescindible en el análisis de áreas afectadas por grandes incendios.

2. Es necesario diseñar un trabajo de campo adecuado a los objetivos del trabajo de evaluación y restauración, utilizando protocolos de muestreo desarrollados específicamente para los trabajos de restauración post-incendio.

\section{DETERMINACIÓN DE LA SUPERFICIE Y DEL PERÍMETRO DEL INCENDIO}

La discriminación de la superficie recorrida por el fuego, aplicando distintas técnicas de medición, suele ser uno de los aspectos que genera mayor discrepancia en la evaluación post-incendio. El levantamiento de la superficie recorrida por 
el fuego se realiza siguiendo principalmente tres procedimientos:

1. Levantamiento con GPS. En donde se recorre el perímetro del incendio con un GPS, ya sea a pie de campo por un operario, o mediante un helicóptero.

2. Fotointerpretación de ortofotos. El perímetro del fuego lo obtiene un observador entrenado dibujando directamente en campo los límites físicos del incendio en una ortofoto.

3. Clasificación de una imagen de satélite (Landsat-ETM+, Aster o similares), basadas originalmente en el uso del Índice Normalizado de Vegetación (NDVI; Díaz-Delgado et al. 2003; Telesca \& Lasaponara, 2006), y más recientemente en el cociente normalizado del área quemada (NBR Normalized Burnt Ratio, Miller \& Yool, 2002, Brewer et al. 2005; Escuín et al. 2006):

$$
\operatorname{NBR}=\left(\rho_{\text {IRC }}-\rho_{\text {SWIR }}\right) /\left(\rho_{\text {IRC }}+\rho_{\text {SWIR }}\right)
$$

Donde $\rho_{\text {IRC }}$ Y $\rho_{\text {swIR }}$ son las reflectancias registradas en el infrarrojo cercano y el infrarrojo medio respectivamente.

En el incendio del P.N. de Torres del Paine se utilizó el índice delta NBR a partir de una imagen previa (Landsat $7 \mathrm{ETM}+$ ) y otra posterior al incendio (ASTER), lo que permitió identificar de forma precisa el área recorrida por el fuego respecto a la zona no afectada (Cocke et al. 2005) (Fig. 3). Los valores obtenidos en esta imagen se consideraron como la medida de perímetro más fiable de acuerdo a los resultados de Key \& Benson (2002; 2005).

El análisis de los valores de los perímetros obtenidos por diferentes sistemas mostró importantes diferencias en los valores de superficie recorrida por el fuego (Tabla 2, Fig. 4) (Coeficiente Kappa de 0,73). Las superficies calculadas usando un GPS y ortofotos subestimaron el valor del área afectada en un 9,7\% (1.667 ha) y un 13,3\% (2.278 ha) respectivamente con respecto a la obtenida usando el índice NBR (Tabla 2) Igualmente, el perímetro medido a partir de la imagen es mayor que el registrado a partir de ortofotos $(-54,55 \mathrm{~km})$ y GPS $(-6,15 \mathrm{~km})$.

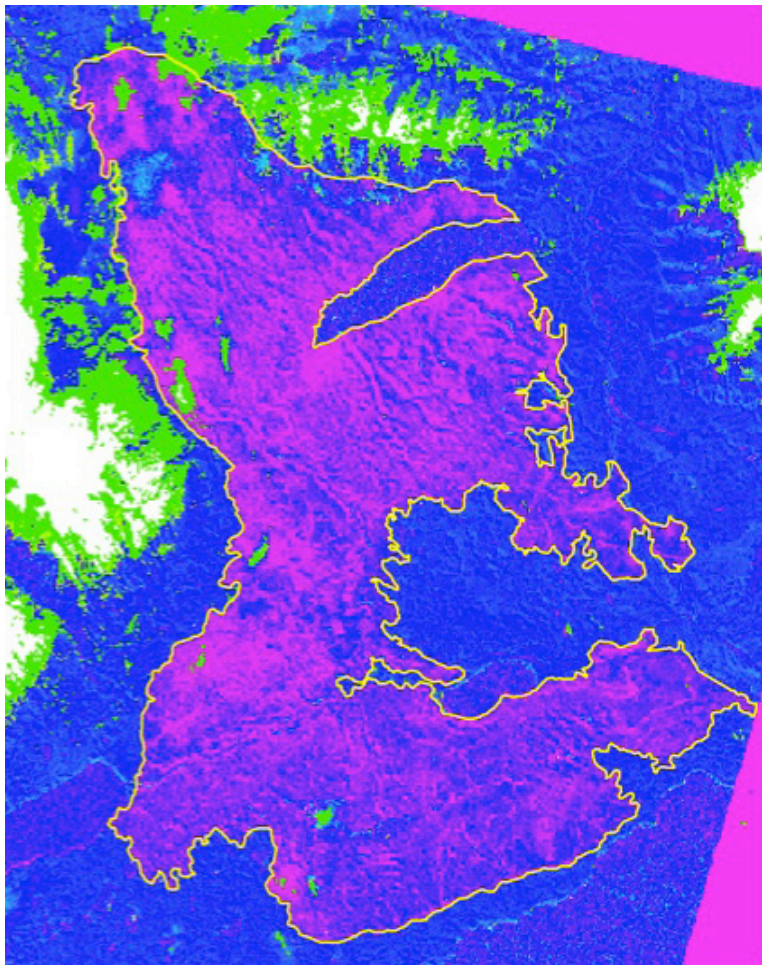

Fig. 3. Perimetro digitalizado sobre una imagen Aster aplicando el índice $\triangle$ NBR (Normalized Burnt Ratio) realzado con un filtro de color. Los tonos malvas y azules oscuros reflejan el área del incendio. Las nubes pueden distinguirse en diferentes tonos de verde.

\section{Recomendaciones}

3. La definición de la superficie recorrida por el fuego, así como su perímetro, es una medida fundamental en el proceso restaurador, aunque los medios empleados y la calidad de los datos deben adecuarse al momento concreto (y la urgencia) de la medición.

4. La clasificación de una imagen satélite (Landsat-ETM+, Aster o similares), mediante el empleo del cociente normalizado del área quemada (NBR), es un procedimiento sencillo y ha mostrado ser la medida de mayor fiabilidad en la determinación de la superficie recorrida por el fuego.

\section{DETERMINACIÓN DE LA VEGETACIÓN PREVIA AL INCENDIO}

Uno de los trabajos más importantes y 

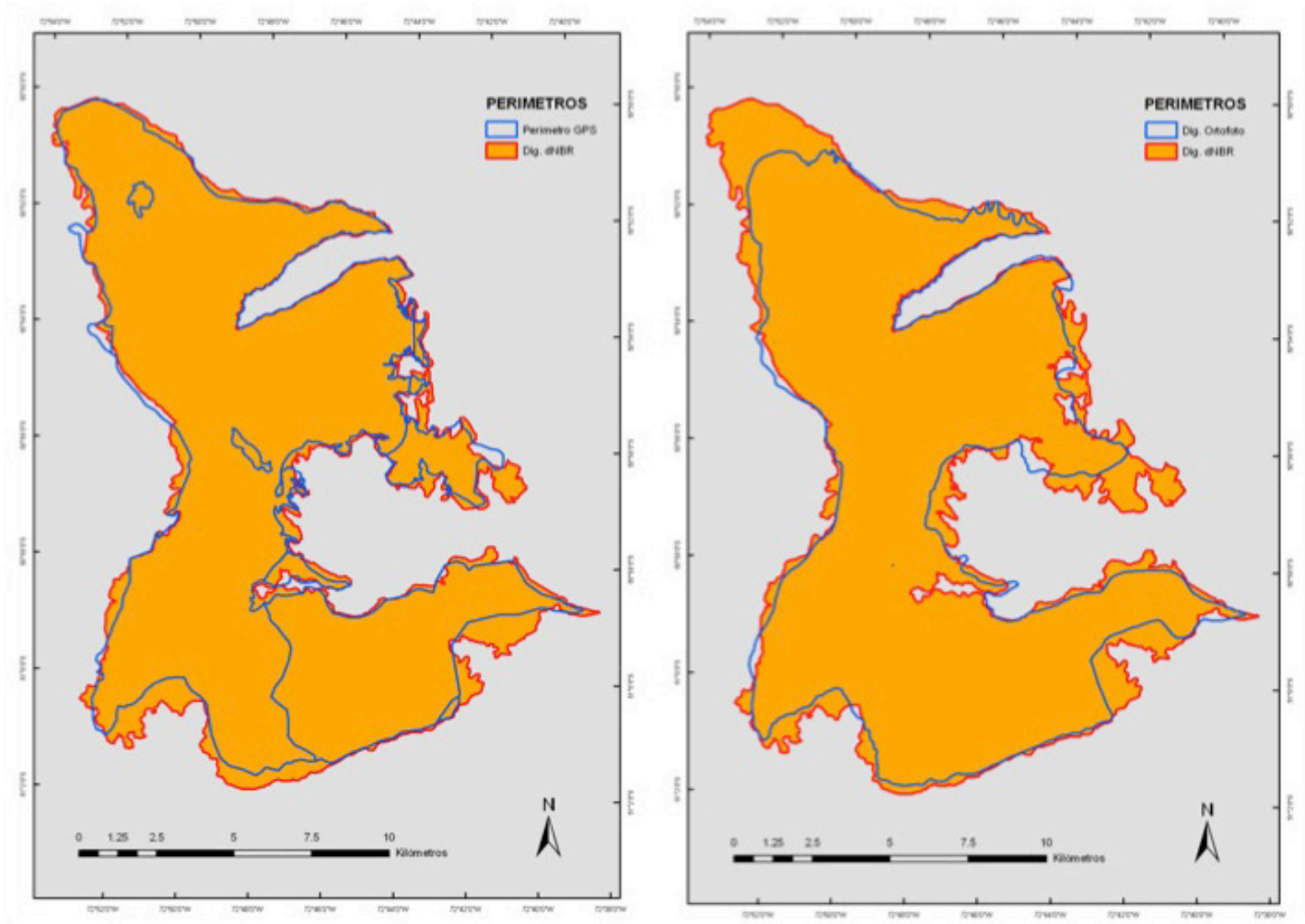

Fig. 4. Comparación del perímetro del incendio de Torres del Paine (2005) resultante mediante la digitalización sobre la imagen aplicando un $\triangle$ NBR con los perímetros obtenidos mediante GPS (a) y fotinterpretación (b).

laboriosos en la evaluación y restauración de daños postincendio consiste en la reconstrucción cartográfica de la vegetación previa al incendio. $\mathrm{Su}$ importancia estriba en primer lugar en la necesidad de reconocer las características del ecosistema dañado, que es, en definitiva, el ecosistema de referencia (sensu Steward T.A.
Pickett) en el proceso restaurador, así como para establecer los modelos dinámicos de respuesta de la vegetación al fuego (Bisson et al. 2008; Kozlowski, 2012). En el caso de las formaciones andino-patagónicos estos procesos se han estudiado para bosques de Nothofagus sp. (Roig et al. 1983; Veblen et al. 1996; Fasggi

Tabla 2. Superficie y perímetro del incendio del P.N. de Torres del Paine (2005) obtenidos mediante la aplicación del índice $\triangle$ NBR (Normalized Burnt Ratio) a una imagen ASTER, la medida con un GPS y el derivado de fotointerpretación.

$$
\text { Superficie afectada (ha) }
$$

Perímetro $(\mathrm{km})$

$\triangle \mathrm{NBR}$

15.471

14.860

1667

2278
158,45

152,30

103,90

6,15

54,55 
\& Cagnoni, 1996; Raffaele \& Veblen, 2001), y tundra magallánica (Roig et al. 1983).

La inexistencia, en muchos casos, de una cartografía previa de la vegetación a una escala apropiada, obliga a recurrir a técnicas de fotointerpretación o de clasificación de imágenes. En muchos casos se han utilizado fotografía aérea pancromática y color, que permite realizar un reconocimiento de áreas de vegetación homogénea (teselación), y definir la estructura y composición de la vegetación en función principalmente de la distribución de los estratos arbóreos y arbustivos. En otros casos se dispone de Mapas de Usos y Coberturas Vegetales a escala variable, como el caso de Catastro Forestal Chileno (CONAFCONAMA, 1997) para una aproximación inicial a la distribución y composición especifica de la vegetación, o bien de cartografía local (Mapa de Vegetación del Parque Nacional de Torres del Paine). Sin embargo, estas cartografías suelen adolecer de falta del detalle adecuado para los trabajos de restauración. Eso es lo que hace que en muchos casos sea preferible elaborar una cartografía propia para describir la vegetación preexistente en el área de estudio.

En el Parque Nacional de Torres del Paine se hizo un cartografía que consideraba siete tipos dominantes de usos del suelo, tres no forestales (ríos, suelo desnudo y nieve) y cuatro categorías forestales determinadas por el subtipo forestal dominante (estepa patagónica, matorral preandino, formaciones de lenga y formaciones de ñirre). La clasificación supervisada se generó a partir de la escena anterior al incendio (Landsat ETM+, 02-10-1999) lo que permitió elaborar un mapa de la vegetación previa al fuego (Tabla 3 , Fig. 5) (Coeficiente Kappa de 0,75).

Los tipos de vegetación obtenidos a partir de la imagen presentan una estructura muy fragmentada, coincidiendo con las descripciones que hace Pisano (1974) de la vegetación para esta zona, dominada por estepas caducifolias y bosques caducifolios magallánicos (Gajardo, 1995; Garay \& Guineo, 2003).

En la superficie afectada por el incendio del P.N. de Torres del Paine (2005) dominaban las formaciones de estepa patagónica, gramíneas perennes de altura media a baja con crecimiento en forma de champas, constituidas por asociaciones de Festuca gracillima Rothm., Festuca magellánica Lam. (Coirón) y Stipa brevipes E. Desv. que frecuentemente están acompañadas por especies arbustivas como Berberis buxifolia Lam. (Calafate), Mulinum spinosum (Cav.) Persoon (Mata barrosa) y Juniella tridens (Lag.) Moldenke. (Mata negra), y de Baccharis magellanica (Lam.) Pers. (Chilco de Magallanes).

Todas estas especies son igualmente constitutivas de las formaciones de matorral pre-andino, de modo que la diferenciación entre estas dos grandes provincias bióticas esta más relacionada con la abundancia relativa de una u otra especie que con la presencia de estas. Las comunidades de matorral quedarían mejor representadas por aquellas zonas donde el estrato dominante lo constituyesen asociaciones de B. buxifolia, M. spinosum, J. tridens, Escalonia rubra (R. et P.) Pers. (Siete camisas), Anarthrophyllum desiderátum (DC.) Benth. (Neneo), y Maytenus magellanica (Lam.) Hook. f. (Leña dura) entre otras especies, dominando en llanuras y terrenos rocosos, en formaciones de matorrales de cobertura variable y de altura media. Las formaciones de mayor talla las constituyen los bosques magallánicos deciduos arbóreos de Nothofagus pumilio Poepp. et Endl. (Lenga) Nothofagus betuloides (Mirb.) Oerst. (Coigüe de Magallanes), y arbustivas de Nothofagus antarctica G. Forst. (Ñirre).

\section{Recomendaciones}

1. El mapa de vegetación previa al incendio constituye la información básica para interpretar la potencial dinámica de respuesta de las comunidades vegetales al impacto producido por el fuego, aunque ésta venga matizada por factores ambientales (pendiente, exposición, estructura, etc.) y aquellos relacionados con el impacto del fuego.

2. La fotointerpretación y/o la clasificación supervisada de imágenes de media o alta resolución (Landsat ETM+, Aster) o alta resolución (RapidEye, WorldView, entre otras) representa la herramienta cartográfica más adecuada para obtener dicha cartografía. 


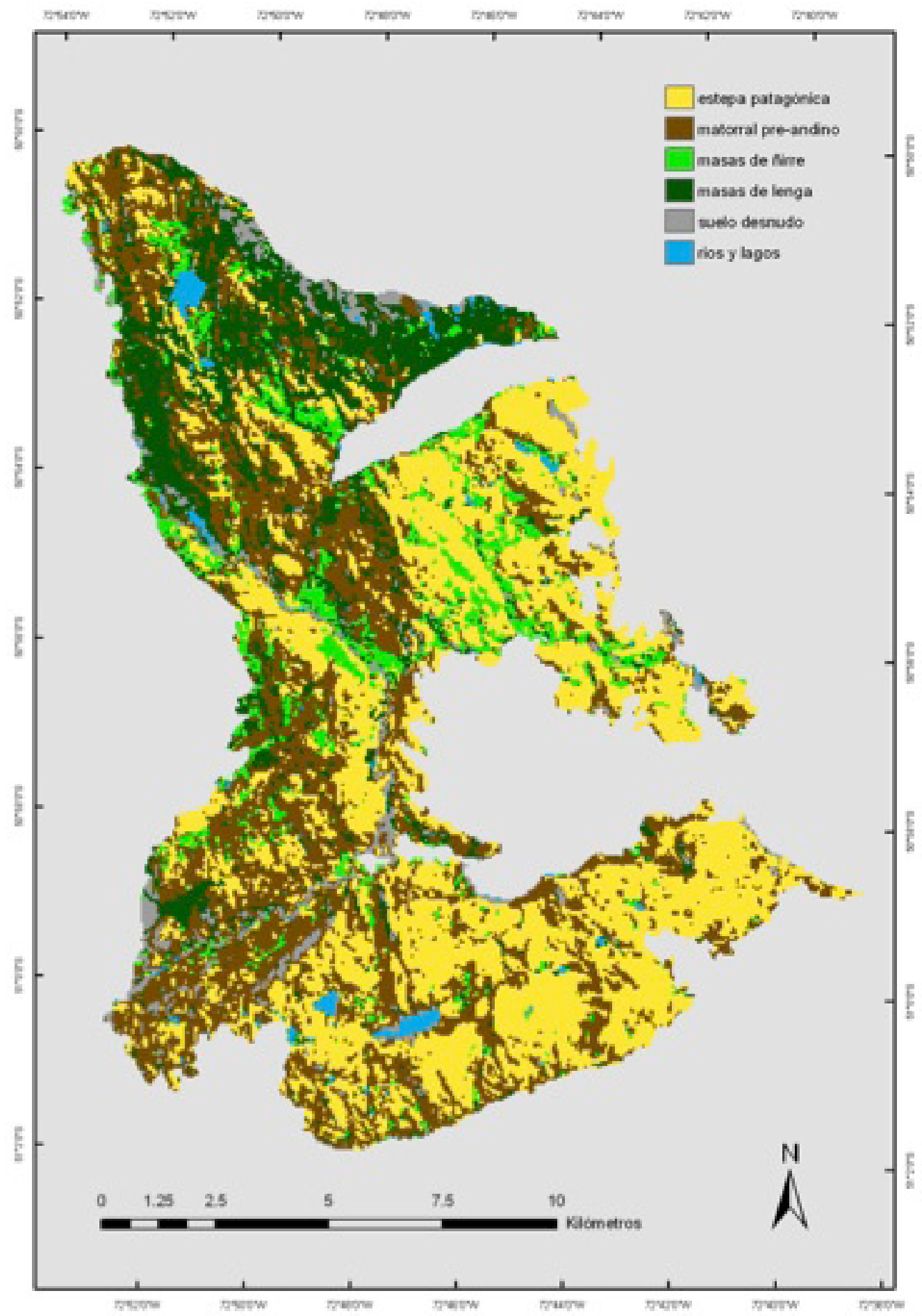

Fig. 5. Mapa de vegetación previa al incendio en el Parque Nacional Torres del Paine (2005) obtenida a partir de la clasificación supervisada de una imagen Landsat-ETM+. 


\section{CARTOGRAFÍA DE SEVERIDAD DE} DAÑOS SOBRE LA VEGETACIÓN

Junto con la evaluación de la vegetación previa al incendio, la generación de una cartografía de severidad de los daños producidos por el fuego, es el otro elemento fundamental para la evaluación y la restauración de grandes incendios. La aplicación de sensores a la evaluación de la severidad es uno de los temas que más se ha desarrollado en los últimos años (Brewer et al. 2005; Gitas et al. 2009; Veraverbeke et al. 2010). La disponibilidad de sensores de adecuada resolución espacial y espectral ha permitido aplicar técnicas de clasificación supervisada, estableciendo una relación entre los valores digitales de la imagen y los valores determinados en campo para discriminar los grados de severidad por incendio (Rogan \& Franklin, 2001; Escuin et al. 2008).

En el incendio del P.N. de Torres del Paine (2005) la cartografía de severidad de daños obtenida mediante la clasificación supervisada de una imagen Aster (Fig. 6) mostró una distribución de los mismos muy heterogénea (Coeficiente Kappa del 0,73). Este hecho, se puede explicar por la diversidad de las comunidades vegetales que integran la zona, y la estructura espacial que presentan, así como por su grado de fragmentación. En la Tabla 3 se observa la superficie afectada según las diferentes formaciones presentes en función de los distintos grados de severidad sufridos. La formación que sufrió más daños fue la estepa patagónica, seguida por las formaciones de matorral preandino, mientras que los tipos forestales de bosques caducifolios de lenga y ñirre fueron afectados en menor superficie (1.558 ha $y$ 989 ha respectivamente).

Las formaciones de estepa patagónica presentaban los daños muy severos en casi el $60 \%$ de su superficie y moderados en cerca del 25\% (Fig. 7). El elevado porcentaje de superficie afectada en grado extremo en estas formaciones es atribuible a las características estructurales de las especies que componen la estepa, que determinan su alta combustibilidad. El fuego, en este tipo de formaciones, se propaga a grandes velocidades y consume la totalidad del combustible en condiciones de arder. Sin embargo, las asociaciones de matorrales fueron las que sufrieron en mayor grado los efectos del fuego, ya que el $86 \%$ (Tabla 3) de su superficie registró una alta severidad de daños. El comportamiento de este tipo de formaciones frente al fuego es parecido al de la estepa, aunque las velocidades de propagación son algo menores que en las zonas donde las especies predominantes son del género Festuca spp. La cantidad de combustible disponible que arde en las formaciones de matorral pre-andino puede llegar a ser el $95 \%$ del total. La relación entre daños extremos y moderados en la categoría de matorral estuvo más compensada (Tabla 3) que en el caso de la estepa, esta circunstancia puede deberse a que las formaciones de Berberis spp. presentan menor combustibilidad (Veblen et al. 1996).

En los bosques caducifolios de lenga la severidad de los daños observados fue extrema en el $32 \%$ de su superficie y moderada en más del 60 \%. El comportamiento del fuego en esta clase de formaciones es muy diferente al esperado en matorrales o estepa. La estratificación vertical que suelen presentar los bosques de lenga, donde el sotobosque está formado básicamente por especies herbáceas, dificulta la propagación del fuego a las copas, junto a una mayor humedad bajo el dosel arbóreo que en las zonas abiertas como la estepa (Veblen et al. 1996). Por otro lado, la relación superficie/volumen de las ramas es más reducida que la de los combustibles finos, por tanto, necesitan más tiempo de exposición a las radiaciones antes de entrar en ignición. En estas circunstancias el fuego se propaga generalmente a través de la hojarasca a menor velocidad que en los otros tipos de formaciones. Todo ello determina que la mayor parte de los daños observados en estas masas sean moderados, estando los daños extremos en lenga localizados en las proximidades del Camping Laguna Azul y en las zonas colindantes al origen del incendio, donde se produjeron fuegos de copas.

En el caso de los arbustos dominados por ñirre, la severidad fue principalmente extrema (47\%), casi doblando el porcentaje de daños moderados (24\%). Las zonas de ñirre que no presentaban daños correspondían en su mayoría a manchas de estas formaciones que emergen dentro de grandes extensiones de estepa. El comportamiento del fuego 


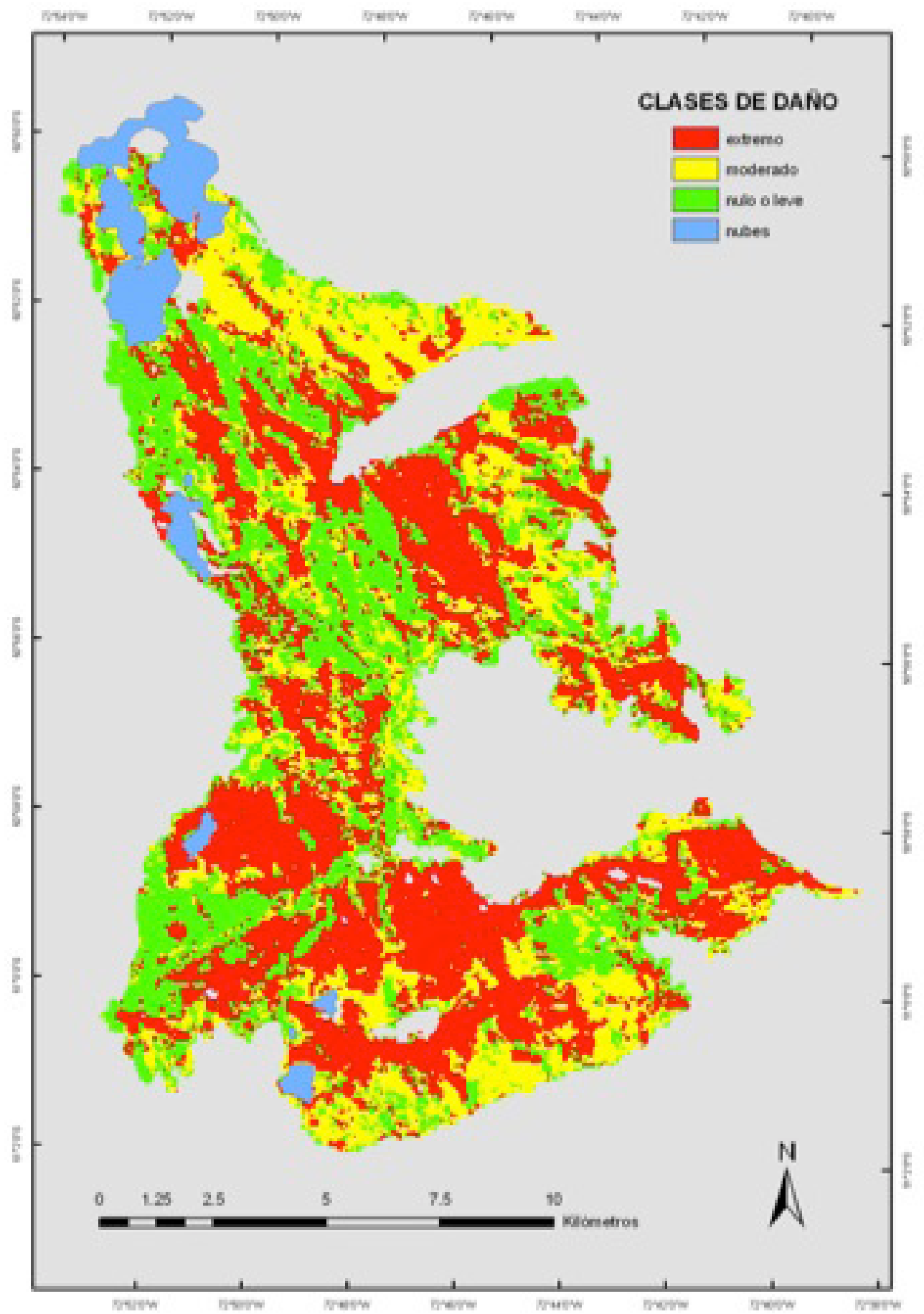

Fig. 6. Mapa de severidad de los daños producidos por el incendio del P.N. de Torres del Paine (2005) obtenido a partir de la clasificación supervisada de una imagen Aster posterior al incendio a partir de la composición de bandas del VIRN y el SWIR más el $\triangle$ NBR. 


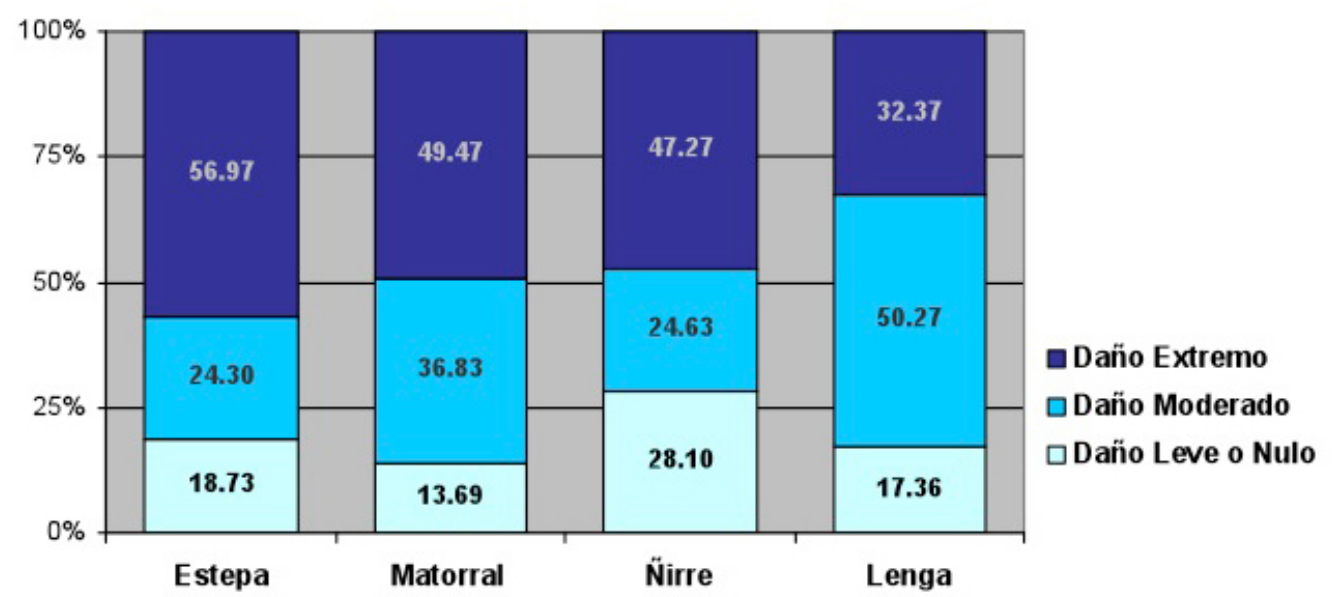

Fig. 7. Porcentaje de superficie según el nivel de severidad (ver texto) para cada tipo de vegetación en el incendio del P.N. de Torres del Paine (2005). Los niveles de severidad están referidos a la superficie evaluada de cada tipo de formación.

Tabla 3. Superficie en hectáreas de los diferentes tipos de vegetación previa al incendio en el área afectada por el incendio del P.N. de Torres del Paine (2005). La superficie se clasifica en función de la severidad de los daños (ver texto). El campo "Otros" representa los suelos desnudos, ríos y lagos que se encuentran dentro del perímetro. La categoría "sin clasificar" corresponde a áreas con nubes o sombras de estas.

\begin{tabular}{cccccc}
\hline & Estepa & Matorral & Nirre & Lenga & Otros \\
\hline Extremo & 3640,1 & 2051,2 & 467,8 & 504,4 & - \\
Moderado & 1552,6 & 1527,1 & 243,8 & 783,3 & - \\
Leve o nulo & 1196,6 & 567,6 & 278,1 & 270,4 & 913,2 \\
Sin clasificar & 494,0 & 1434,3 & 257,1 & 877,3 & 91,5 \\
Superficie (ha) & 6383,3 & 5580,0 & 1246,8 & 2435,4 & \\
\hline
\end{tabular}

en formaciones de ñirre difiere mucho de unos sitios a otros, debido a la variedad de formas con que se presenta. En formaciones donde predomina el porte arbustivo alto, como en las zonas cercanas a la Laguna Cebolla y a la cordillera del Paine, la distribución de daños fue similar a la que presentó la lenga, mientras que en el resto del área donde el nirre aparecía con porte arbustivo o achaparrado, tuvo una distribución y tipo de daños similares al matorral preandino.

\section{Recomendaciones}

1. El mapa de severidad de daños producidos por el fuego sobre la vegetación constituye, junto al mapa de vegetación previa, la información cartográfica más relevante para interpretar la potencial dinámica de respuesta de las comunidades vegetales al impacto producido por el fuego.

2. La clasificación supervisada de imágenes de media o alta resolución (Landsat ETM+, Aster) o alta resolución (RapidEye, WorldView) representa la herramienta de teledetección más adecuada para obtener dicha cartografía. 3. En la Patagonia, donde las lluvias son abundantes y bien repartidas a lo largo del año, se recomienda que el análisis de severidad se haga a partir de imágenes obtenidas a lo sumo dos semanas posteriores al incendio. 


\section{INTEGRACIÓN DE INFORMACIÓN AMBIENTAL PARA LA DEFINICIÓN DE ACTUACIONES DE RESTAURACIÓN}

\section{Identificación de áreas \\ prioritarias de actuación}

El análisis del potencial de recuperación de la vegetación post-incendio debe implicar variables tales como la vegetación previa (composición de las especies, la riqueza, la diversidad de la comunidad, etc.) y la heterogeneidad espacial (Bisson et al. 2008; Lhermitte et al. 2011; Altamirano et al. 2013). Por tanto, la cartografía obtenida en los epígrafes previos representa la información básica para elaborar las propuestas de restauración, en particular en lo referente a la selección de áreas prioritarias de actuación y la definición de las técnicas más adecuadas de restauración. La delimitación de áreas de restauración prioritaria es fundamental puesto que se asume que los recursos a invertir en la restauración de áreas afectadas por grandes incendios siempre son limitados.

En el caso concreto del incendio del P. N. de Torres del Paine (2005) se utilizaron los siguientes criterios para la definición de las áreas de actuación:

1. Priorización de zonas dominadas por bosque magallánico deciduo de lenga y ñirre, donde la severidad de los daños había sido más importante (moderado y extremo). Esta decisión estuvo justificaba por el hecho de que estas especies presentan resilencias inferiores al resto de los ecosistemas afectados (Veblen et al. 1996; Raffaele \& Veblen, 2001), por lo que resulta necesario impulsar su restablecimiento con medidas de apoyo y con plantaciones.

2. No se priorizaron las zonas dominadas por estepa patagónica y matorral pre-andino, incluso cuando la severidad fue extrema en la mayor parte de los casos, ya que se trata de formaciones que presentan una alta resilencia al fuego (Roig et al. 1983), por lo que los procesos de regeneración natural aseguran su restablecimiento.

3. Actuaciones próximas a las zonas limítrofes a los accesos principales al Parque
Nacional, dado el carácter recreativo y turístico de este espacio.

Las áreas prioritarias de restauración fueron el resultado del cruce realizado entre la cartografía de vegetación previa al incendio (epígrafe 4) y por la correspondiente a la severidad del incendio (epígrafe 5), junto con información ambiental básica (topografía, suelos, y exposición visual). Sin embargo, el nivel de desagregación de la leyenda obtenida al cruzar estas capas de información puede ser excesivo de cara a la definición de las actuaciones más urgentes de restauración, por lo que se realizó una recodificación del mismo en base a los siguientes parámetros (Fig. 8):

- Presencia o ausencia de estrato arbóreo (lenga y ñirre).

- Pendiente.

- Fracción de cabida cubierta del estrato arbóreo.

\section{Definición de actuaciones de restauración}

Por último, el mapa de actuaciones de restauración incluye las propuestas de restauración en función de criterios ecológicos, de protección, de uso público y económico.

\section{Selección de especies}

La selección de las especies propuestas en los trabajos de restauración obedeció principalmente a criterios ecológicos, en particular en las condiciones edafoclimáticas del sitio. En este sentido, hay que recordar que la zona afectada por el incendio está situada sobre dos grandes regiones vegetales: la dominada por estepas caducifolias y los bosques caducifolios magallánicos caracterizados por la presencia constante de lenga (Nothofagus pumilio). En el caso de las formaciones arbóreas, éstas se desarrollan en aquellos lugares donde las precipitaciones son superiores a los $400 \mathrm{~mm}$ anuales y ha sido posible la formación de suelos forestales (Gajardo, 1995). Por tanto, las principales especies forestales potenciales para la restauración de la zona son $N$. pumilio, $N$. 


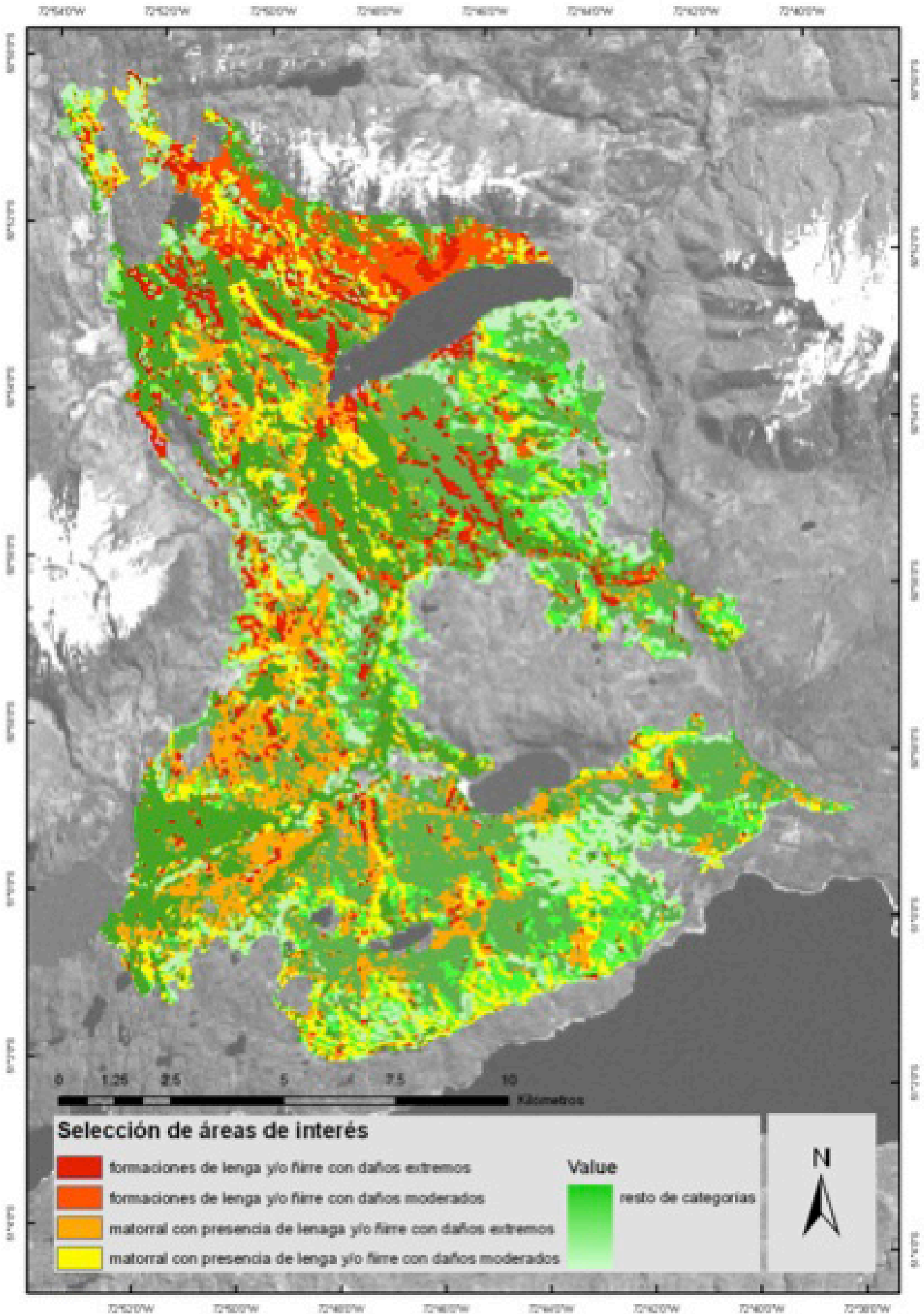

Fig. 8. Mapa de áreas prioritarias de restauración seleccionadas a partir de la combinación del mapa de vegetación previa al incendio y de la cartografía de severidad. 


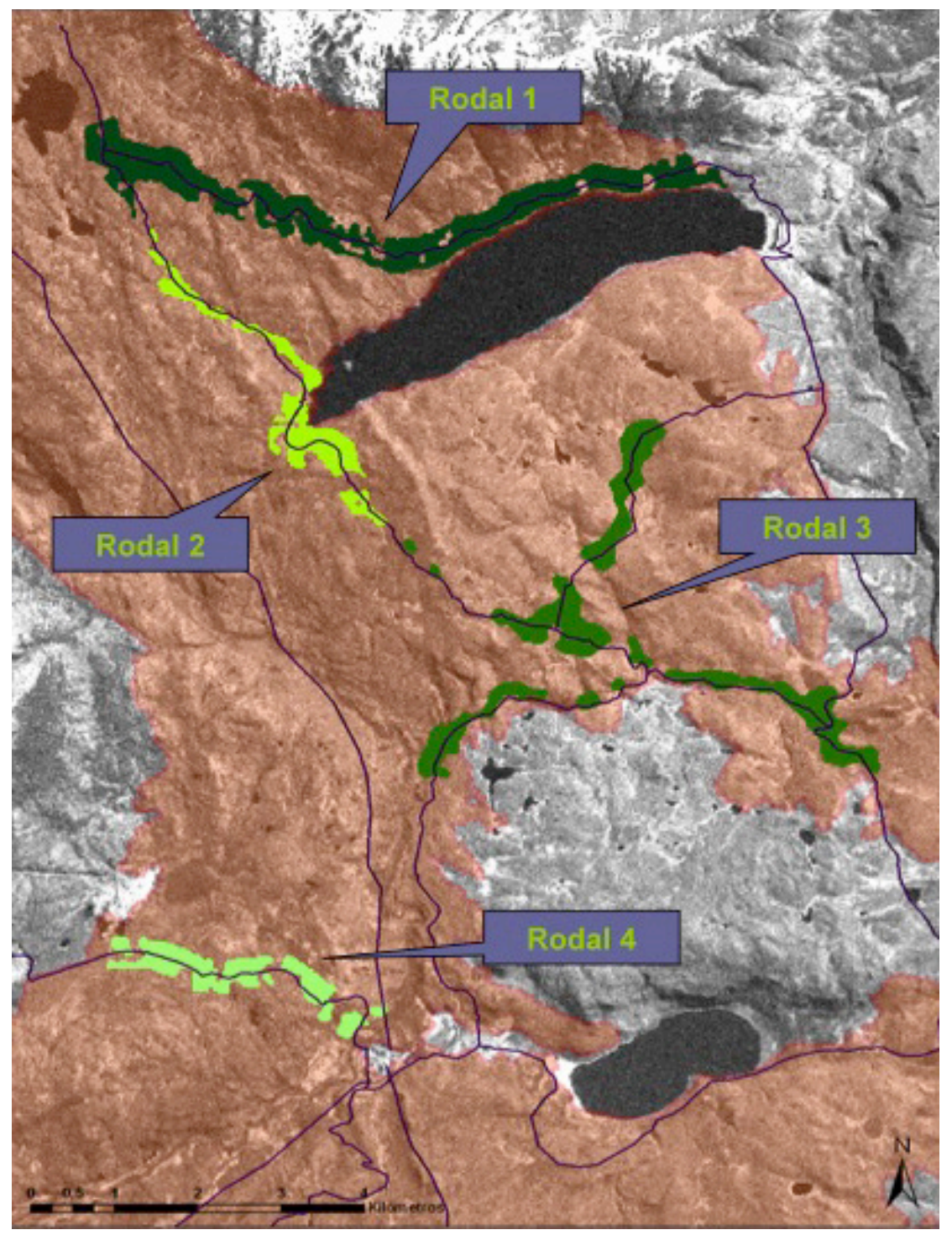

Fig. 9. Mapa de rodales de actuación (ver tablas 4 y 5) para la superficie afectada por el incendio del P.N. de Torres del Paine (2005).

antarctica, $N$. betuloides y en menor medida Drimys winteri J. R. et Forster (Canelo).

\section{RODALIZACIÓN DE LAS ÁREAS DE RESTAURACIÓN}

La fase final de las propuestas de restauración es la cartografía del plan de restauración, que consiste en un mapa que incluye los rodales definitivos de actuación y la técnica a emplear en cada caso. En el incendio del P.N. de Torres del
Paine (2005) se propusieron los siguientes rodales de actuación (Fig. 9; Tabla 4 y 5):

En el Rodal 1 los suelos presentes son profundos, con buen drenaje y bien desarrollados. Esto los hace ideales para el establecimiento de lenga, la elección de esta especie la refuerza el hecho de que ésta fuera la especie predominante en todo el rodal.

En el Rodal 2 los suelos tienen profundidades variables, pero en general están bien desarrollados. Se trata de un área de transición entre las masas 
TABLA 4. Principales característica ambientales de los rodales de restauración en el área afectada por el incendio del P.N. de Torres del Paine (2005).

\begin{tabular}{llllll}
\hline Rodales & Superficie (ha) & Pendiente (\%) & Exposición & Vegetación & $\begin{array}{l}\text { Severidad de } \\
\text { daños }\end{array}$ \\
\hline Rodal 1 & 309,5 & variable & Umbría & $\begin{array}{l}\text { Arbolado de lenga } \\
\text { adulto }\end{array}$ & Extremo \\
Rodal 2 & 109,5 & $<35$ & Solana & $\begin{array}{l}\text { Formación mixta de lenga } \\
\text { y ñirre }\end{array}$ & Extremo \\
Rodal 3 & 260 & variable & Variable & $\begin{array}{l}\text { Formación mixta de ñirre y } \\
\text { matorral patagónico }\end{array}$ & Extremo \\
Rodal 4 & 103,5 & $<20$ & Solana & Formación de ñirre & Extremo \\
\hline
\end{tabular}

dominadas por lenga y ñirre. En las operaciones de densificación y enriquecimiento, descritas para este rodal, se recomienda el uso de lenga y ñirre, según las observaciones en el terreno.

En los Rodales 3 y 4 los suelos son más delgados, y no se presentan tan bien desarrollados. En estas condiciones más extremas de sitio el ñirre es la especie que mejor se adapta. La vegetación preexistente en estos rodales era de ñirre generalmente con forma del tipo achaparrado que se desarrollaba en las laderas donde las condiciones de drenaje son mejores.

La elección de los tratamientos de establecimiento (eliminación de vegetación muerta y procedimiento de preparación del terreno), así como los cuidados culturales a las plantaciones se realizaron de acuerdo a las propuestas de actuación para cada rodal, y con el objetivo de reducir al mínimo el impacto de las actuaciones de restauración. Dichos tratamientos estuvieron determinados por las operaciones de restauración diseñadas para cada sitio y por las pendientes

TABLA 5. Rodales de actuación y principales propuestas de restauración para cada rodal en el área afectada por el incendio del P.N. de Torres del Paine (2005).

\begin{tabular}{|c|c|c|c|c|}
\hline & Actuaciones & Especies seleccionadas & $\begin{array}{l}\text { Procedimientos de } \\
\text { preparación del terreno }\end{array}$ & Acotamientos \\
\hline Rodal 1 & $\begin{array}{l}\text { Franja de restauración } \\
\text { ( } 50 \text { m a ambos lados). }\end{array}$ & Nothofagus pumilio & Ahoyado manual & Individuales \\
\hline Rodal 2 & $\begin{array}{l}\text { Enriquecimiento y densificaciones } \\
\text { en manchas singulares de lenga. }\end{array}$ & $\begin{array}{l}\text { Nothofagus pumilio } \\
\text { Nothofagus antarctica }\end{array}$ & Ahoyado mecanizado & Perimetrales \\
\hline Rodal 3 & $\begin{array}{l}\text { Franja de restauración } \\
\text { (50 m margen norte). } \\
\text { Enriquecimiento y densificaciones } \\
\text { en manchas singulares de ñirre. }\end{array}$ & Nothofagus antarctica & Ahoyado manual & Perimetrales \\
\hline \multirow[b]{2}{*}{ Rodal 4} & $\begin{array}{l}\text { Franja de restauración } \\
\text { (50 m a ambos lados). }\end{array}$ & \multirow[b]{2}{*}{ Nothofagus antarctica } & \multirow[b]{2}{*}{ Ahoyado mecanizado } & \multirow[b]{2}{*}{ Individuales } \\
\hline & $\begin{array}{l}\text { Limpieza y eliminación de } \\
\text { material muerto en masas de } \\
\text { ñirre. }\end{array}$ & & & \\
\hline
\end{tabular}


dominantes.

\section{Recomendaciones}

1. La integración de la cartografía de la vegetación previa al incendio, el mapa de severidad, y la información ambiental disponible (pendiente, orientación, y suelos principalmente) permite identificar las áreas de mayor potencial de recuperación de la vegetación post-incendio, teniendo en cuanta la vegetación previa (composición de las especies, la riqueza, la diversidad de la comunidad, etc.) y la heterogeneidad espacial.

2. La fase final del plan de restauración debe ser elaborar una cartografía que incluya los rodales definitivos de actuación y las decisiones técnicas más relevantes del proceso restaurador (elección de especie, establecimiento, cuidados culturales, evaluación, etc.).

\section{CONCLUSIONES}

En este trabajo se presentan los resultados obtenidos al aplicar la metodología para la evaluación y restauración de áreas afectadas por grandes incendios desarrollados de forma conjunta entre la Corporación Nacional Forestal (CONAF) y la Universidad de Córdoba (España) para el caso del incendio del Parque Nacional de Torres del Paine (2005). La CONAF como administración responsable de la gestión y restauración de los ecosistemas forestales chilenos cuenta con una herramienta metodológica que permite actuar de forma rápida después de grandes incendios, y obtener información ambiental fiable para tomar las decisiones más urgentes para la restauración de los ecosistemas afectados, encaminadas a conservar y restaurar las zonas más sensibles. La existencia de una metodología de referencia facilita la elaboración de planes y proyectos de restauración de áreas afectadas por grandes incendios en Chile, cuya ejecución palie, en lo posible, buena parte de los efectos directos $e$ indirectos causados por los incendios forestales. El trabajo de análisis de la información procedentes de sensores remotos de media (Landsat-ETM+ y ASTER) y alta resolución espacial (RapidEye, WordView) es rápido, de costo reducido y de alta fiabilidad lo que la convierte una buena alternativa para el estudio postincendio en áreas afectadas por grandes incendios, adecuando metodologías análogas implantadas ya en otros países.

Los resultados en el caso del incendio del P.N. de Torres del Paine (2005) confirman la utilidad de esta metodología para elaborar cartografía temática que puede aplicarse para definir las zonas de restauración, facilitando especialmente la selección de áreas prioritarias de actuación.

\section{AGRADECIMIENTOS}

Los autores de este trabajo quieren agradecer el apoyo material y humano brindado por la CONAF en Santiago de Chile y en Punta Arenas para el desarrollo de esta investigación. También queremos agradecer a todo el personal del Parque Nacional Torres del Paine su cordialidad, ayuda y dedicación en el trabajo de campo y en la interpretación y enseñanza de la belleza y complejidad de la vegetación patagónica. El proyecto se ha realizado con ayuda del Programa Propio de la Universidad de Córdoba.

\section{LITERATURA CITADA}

Alloza, J.A., García, S., Gimeno, T., Baeza, M. J., \& Vallejo, V.R. (2014). Guía técnica para la gestión de montes quemados. Ministerio de Agricultura, Alimentación y Medio Ambiente.

Altamirano, A., Salas, C., Yaitul, V., SmithRamirez, C., \& Ávila, A. (2013). Influencia de la heterogeneidad del paisaje en la ocurrencia de incendios forestales en Chile Central. Revista de Geografia Norte Grande, 55, 157-170.

Bisson, M., Fornaciai, A., Coli, A., Mazzarini, F., \& Pareschi, M. (2008). The Vegetation Resilience After Fire (VRAF) index: development, implementation and an illustration from central Italy. International Journal of Applied Earth Observation and Geoinformation 10, 312-329.

Brewer, C.K., Winne, J.C., Redmond, R.L., Opitz, D.W., \& Mangrich, M.V. (2005). Classifying and mapping wildfire severity: A comparison of methods. Photogrammetric Engineering 
and Remote Sensing 71, 1311-1320.

Brown, R., Agee, J. \& Franklin, J. (2004). Forest Restoration and Fire: Principles in the context of Place. Conservation Biology 18, 903-912.

Castro, J., Navarro Cerrillo, R.Mª., Guzmán Álvarez, J.R., Zamora, R., \& Bautista, S. (2009). ¿Es conveniente retirar la madera quemada tras un incendio forestal? Quercus, 281, 36-41.

Castillo, M., Julio, G., \& Garfias, R. (2014). Current status of risk and prognosis of forest fires in Chile. Progress and future challenges. In D. Paton (Ed.), Wildfire Hazards, Risks and Disasters (pp. 59-75). Amsterdam, Elsevier.

Castillo, M. (2006). El cambio del paisaje vegetal afectado por incendios en la Zona Mediterránea Costera de la V Región. Tesis de Grado de Magíster en Geografía. Universidad de Chile.

Cocke A., Fule, P., \& Crouse, J. (2005). Comparison of burn severity assessments using differenced normalized burn ratio $(\triangle \mathrm{NBR})$ and ground data. International Journal of Wildland Fire 14, 189-198.

CONAF, (2015). Estadísticas sobre ocurrencia y causa de incendios forestales. http:// www.conaf.cl/incendios-forestales/. Acceso 28 febrero 2015.

CONAF-CONAMA, (1997). Catastro y evaluación de los recursos vegetacionales nativos de Chile. Corporación Nacional Forestal, Santiago, Chile.

Consejería de Medio Ambiente, (2006). Restauración de zonas incendiadas en Andalucía. Consejería de Medio Ambiente, Sevilla, España.

Csiszar, I., Loboda, T., Frenchb, N., Giglioc, L., \& Hockenberryb, T. (2004). A multi-sensor approach to fine-scale fire characterization. http://www.isprs.org/publications/related/ ISRSE/html/papers/598.pdf. Acceso 12 diciembre 2014.

Cuevas-Gonzalez, M., Gerard, F., Baltzer, H., \& Riano, D. (2009). Analysing forest recovery after wildfire disturbance in boreal Siberia using remotely sensed vegetation indices. Global Change Biology 15, 561-577.

Daskalakou, E. \& Thanos, C. (1997). Post-fire establishment and survival of Aleppo pine seedlings. In: P. Balabanis, G. Eftichidis, R. Fantechi (Eds.) Forest fire risk and management. (pp. 357-368). European Commission, Directorate General XII, Science, Research and Development, Luxembourg.

Díaz-Delgado, R., Lloret, F., \& Pons, X. (2003). Influence of fire severity on plant regeneration by means of remote sensing. International Journal of Remote Sensing 24, 1751-1763.

Escuin, S., Fernández Rebollo, P., \& Navarro Cerrillo, R.M ${ }^{a}$. (2003). Aplicación de escenas Landsat a la asignación de grados de afectación producidos por incendios forestales. Revista de Teledetección, 17, 77-87.

Escuin, S., Navarro Cerrillo, R.Ma ., \& Fernández, P. (2006). Assessment of post fire vegetation covers using spectral mixture analysis. Application and comparison of different endmember characterization methods. Investigación Agraria. Sistemas y Recursos Forestales, 15, 107-119.

Escuín, S., Navarro Cerrillo, R. Mª ., \& Fernández, P. (2008). Fire severity assessment by using NBR (Normalized Burn Ratio) and NDVI Normalized Difference Vegetation Index) derived from LANDSAT TM/ETM images. International Journal of Remote Sensing, 29, 1053-1073.

Fasggi, A., \& Cagnoni, M. (1996). Comparación florística de bosques mixtos de coihue y ciprés afectados por incendios en el noroeste de Chubut, Argentina. Multequina 5, 1323.

Fernández, I., Morales, N., Olivares, L., Salvatierra, J., Gómez, M., \& Montenegro, G. (2010). Restauración ecológica para ecosistemas nativos afectados por incendios forestales. Santiago, Chile: Editorial Pontificia Universidad Católica de Chile - Corporación Nacional Forestal.

Gajardo, R. (1995). La vegetación natural de Chile: clasificación y distribución geográfica. Santiago, Chile: Editorial Universitaria y Corporación Nacional Forestal.

Garay G., \& Guinea, O. (2003). Fauna, flora y 
montaña. Torres del Paine. Punta Arenas, Chile: Editorial Amigos de la Vida Silvestre.

Gitas, I., De Santis, A. \& Mitri, G. (2009). Remote sensing of burn severity. In: Chuvieco, E. (Ed.), Earth observation of wildland fires in mediterranean ecosystems (pp. 129148). Berlin: Springer- Verlag.

Gitas, I., Mitri, G., Veraverbeke, S. \& Polychronaki, A. (2012). Advances in Remote Sensing of Post-Fire Vegetation Recovery Monitoring-A review. INTECH Open Access Publisher.

Gouveia, C., DaCamara, C., \& Trigo, R. (2010). Post-fire vegetation recovery in Portugal based on spot/vegetation data. Natural Hazards and Earth System Sciences 10, 673-684.

Hernández-Clemente R., Navarro Cerrillo, R. Ma . Hernández-Bermejo, E., Escuin Royo, S., García-Porras, A., \& Sánchez de la Orden, M. (2007). Regeneración y cambios de diversidad en grandes incendios a partir de imágenes de satélite LANDSAT TM y ETM+. Cuadernos de Investigación Geográfica, 33, 85-100.

Hernández-Clemente, R.; Navarro Cerrillo, R.M ${ }^{a}$., Hernández Bermejo, E., \& Gitas, I. (2009 a). Monitoring post-fire regeneration in Mediterranean ecosystems by employing multitemporal satellite imagery. International Journal of Wildland Fire, 18, 1-11.

Hernandez-Clemente, R., Navarro Cerrillo, R., Hernandez-Bermejo, J., Escuin, S., \& Kasimis, N. (2009 b). Analysis of postfire vegetation dynamics of Mediterranean shrub species based on terrestrial and NDVI data. Environmental Management, 43, 876887.

Hudak, A. T., Robichaud, P. R., Evans, J. B., Clark, J., Lannom, K., Morgan, P., \& Stone, C. (2004). Field validation of Burned Area Reflectance Classification (BARC) products for post fire assessment. In: Remote sensing for field users: proceedings of the tenth Forest Service Remote Sensing Applications Conference, Salt Lake City, Utah, April 5-9, 2004, [CD-ROM]. Bethesda, Md.: American Society for Photogrammetry and Remote Sensing.

Keeley, J. (2009). Fire intensity, Fire severity and burn severity: a brief review and suggested usage. International Journal of Wildland Fire, 18,116-126.

Key C., \& Benson, N. (2002). Remote sensing measure of severity, the normalized burn ratio. Fire effects monitoring and inventory protocol, landscape assessment. http://www.fire.org/firemon/lc.htm. Acceso 1 febrero 2015.

Key, C., \& Benson, N. (2005). Landscape assessment: remote sensing of severity, the normalized burn ratio and ground measure of severity, the composite burn index. In: D. Lutes, R. Keane, J. Caratti, C. Key, N. Benson, \& L. Gangi (Eds) FIREMON: fire effects monitoring and inventory system (RMRS-GTR-164-CD:LA1-LA51). Utah, USA, United States Department of Agriculture, Rocky Mountain Research Station.

Kozlowski, T.T. (Ed.). (2012). Fire and ecosystems. Amsterdam, Elsevier.

Lhermitte, S., Verbesselt, J., Verstraeten, W.W., Veraverbeke, S., \& Coppin, P. (2011). Assessing intra-annual vegetation regrowth after fire using the pixel based regeneration index. ISPRS Journal of Photogrammetry and Remote Sensing, 66, 17-27.

Madsen, M.D., Kostka, S.J., Inouye, A.L., \& Zvirzdin, D.L. (2012). Postfire restoration of soil hydrology and wildland vegetation using surfactant seed coating technology. Rangeland Ecology \& Management, 65, 253-259.

Miller H., \& Yool, S. (2002). Mapping forest post-fire canopy consumption in several overstory types using multi-temporal landsat TM and ETM data. Remote Sensing of Environment, 82, 481-496.

Mitri, G., \& Gitas, I.Z. (2010). Mapping postfire vegetation recovery using EO-1 Hyperion imagery. IEEE Transactions on Geoscience and Remote Sensing, 48, 1613-1618.

Navarro Cerrillo, R.M., Crespo, R., Fernández, P., \& Escuín, S. (2004). Manual para la evaluación de grados de afectación producidos por un incendio. Aplicación 
de imágenes Landsat-TM y ETM+ a su caracterización y seguimiento. ETSI Agrónomos y de Montes. Departamento de Ingeniería Rural. Universidad de Córdoba y Consejerita de Medio Ambiente.

Navarrom Cerrillo, R. Ma . Haya, A., García Ferrer, A., Hernández, R.; Duhalde, P.; González, L. (2008). Caracterización de la situación posincendio en el área afectada por el incendio de 2005 en el Parque Nacional de Torres del Paine (Chile) a partir de imágenes multiespectrales. Revista Chilena de Historia Natural, 81, 95-110.

Onodera, S.I., \& van Stan II, J.T. (2011). Effect of forest fires on hydrology and biogeochemistry of watersheds. In Levia, D.F., Carlyle-Moses, D., Tanaka, T. (Eds.) Forest Hydrology and Biogeochemistry (pp. 599-621). Netherlands, Springer.

Pickett, S. T., \& Cadenasso, M. L. (2002). The ecosystem as a multidimensional concept: meaning, model, and metaphor. Ecosystems, 5(1), 1-10.

Pisano, E. (1974). Estudio ecológico de la región continental sur del área andino patagónica II. Contribución a la fitogeografía de la zona del Parque Nacional Torres del Paine. Anales del Instituto de la Patagonia, 5, 59-104.

Raffaele E., \& Veblen, T.T. (2001). Effects of cattle razing on early postfire regeneration of matorral in northwest Patagonia, Argentina. Natural Areas Journal, 21, 243-249.

Rogan, J. \& Franklin, J. (2001). Mapping wildfire burn severity in southern California forests and shrublands using Enhanced Thematic Mapper imagery. Geocarto International, 16, 1-11.

Roig F., Dollenz O., \& Méndez E. (1983). Tundra y bosque magallánico. Su dinamismo en el sur de Chile. Serie Científica, 30, 5-10.

Sankey, T., Moffet, C. \& Weber, K. (2008). Postfire recovery of sagebrush communities: assessment using SPOT-5 and very largescale aerial imagery. Rangeland Ecology and Management, 61, 598-604.

Telesca, L. \& Lasaponara, R. (2006). Pre- and postfire behavioral trends revealed in satellite
NDVI time series. Geophysical Research Letters, 33, (L14401).

Unit, N.H. (2011). Development of a methodology for the analysis of socio-economic impact of forest fires in Europe. Development, 9, 13.

Vallejo, V.R., Arianoutsou, M., \& Moreira, F. (2012). Fire ecology and post-fire restoration approaches in Southern European forest types. In F. Moreira, M. Arianoutsou, P. Corona, J. De las Heras, (Eds.) PostFire Management and Restoration of Southern European Forests (pp. 93-119). Netherlands, Springer.

van Leeuwen, W., Casady, G., Neary, D., Bautista, S., Alloza, J., Carmel, J., Wittenberg, L., Malkinson, D., \& Orr, B. (2010). Monitoring post-wildfire vegetation response with remotely sensed time series data in Spain, USA and Israel. International Journal of Wildland Fire, 19, 75-93.

van Leeuwen, W. J. (2008). Monitoring the effects of forest restoration treatments on post-fire vegetation recovery with MODIS multitemporal data. Sensors, 8(3), 20172042.

van Wagtendonk, J., Root, R., Key, C., \& Running, S. (2004). Comparison of AVIRIS and Landsat ETM+ detection capabilities for burn severity. International Journal of Wildland Fire, 92, 397-408.

Veblen T., Hill R., \& Read Y. (1996). The ecology and biogeography of Nothofagus forests. Yale University Press, New Haven, Connecticut, USA.

Veraverbeke, S., Lhermitte, S., Verstraeten, W. W. \& Goossens, R. (2010). The temporal dimension of differenced Normalized Burn Ratio (dNBR) fire/burn severity studies: the case of the large 2007 Peloponnese wildfires in Greece. Remote Sensing of Environment, 114, 2548-2563.

Wittenberg, L., Malkinson, D., Beeri, O., Halotzy, A., \& Tesler, N. (2007). Spatial and temporal patterns of vegetation recovery following sequences of forest fires in a Mediterranan landscape, Mt. Carmel Israel. Catena, 71, 76-83. 
